\title{
Methanolic extract of Celosia argentea var. crista leaves modulates glucose homeostasis and abates oxidative hepatic injury in diabetic rats
}

\author{
R. U. Hamzah ${ }^{1}$ - A. R. Lawal $^{1}$ • F. M. Madaki ${ }^{1}$ • O. L. Erukainure ${ }^{2}$
}

Received: 21 July 2017 / Accepted: 8 March 2018 / Published online: 9 April 2018

(C) The Author(s) 2018

\begin{abstract}
Celosia argentea commonly known as cockscomb plant is widely used in folkloric medicine in the treatment and management of diabetes mellitus. The effect of methanolic extract of Celosia argentea var. cristata L. (CAVCL) leaves on blood glucose level, superoxide dismutase (SOD), catalase (CAT), alanine aminotransferase (ALT), aspartate aminotransferase (AST), alkaline phosphatase (ALP) activities, and malondialdehyde (MDA) level were evaluated in diabetic rats. Five groups of male albino rats consisting of 5 animals each were used for the present study. They were grouped as normal control, diabetic control, diabetic administered with 250 and $750 \mathrm{mg} / \mathrm{kg}$ b.w C. argentea, and $5 \mathrm{mg} / \mathrm{kg}$ b.w glibenclamide. Diabetes was induced with alloxan monohydrate intraperitoneally at $120 \mathrm{mg} / \mathrm{kg}$ b.w. The control and diabetic groups were given distilled water and rat chow for 21 days. Blood glucose level of each group was estimated every week, and at the end of the experiment, SOD, CAT, MDA and serum ALP, and AST and ALT activities were assayed in the liver and serum respectively of the experimental animals. The results showed a significant increase $(p<0.05)$ in serum AST, ALP, and ALT activities and reduction in SOD and CAT activities compared with normal control groups. The extract at both doses significantly lowered the high levels of the serum enzymes and increased the level of CAT and SOD. These results indicate an anti-hyperglycemia and antioxidative protective effect of C. argentea leaves.
\end{abstract}

Keywords Celosia argentea $\cdot$ Alloxan-induced diabetes $\cdot$ Free radicals $\cdot$ Hyperglycemia

\section{Introduction}

Diabetes mellitus (DM) is a chronic metabolic disorder characterized by chronic hyperglycemia with impaired carbohydrate, protein, and fatty acid metabolisms arising from deficiencies in insulin secretion, action, or both (WHO 1999). It is characterized by increased hyperglycemia resulting from defective production or action of insulin, leading to several complications such as cardiovascular, renal, neurological, and ocular disorders (Erukainure et al. 2013). Growing evidence suggests that oxidative stress resulting from increased hyperglycemia plays a significant effect in the pathogenesis of DM

R. U. Hamzah

rabiune@yahoo.com; rabiola@ futminna.edu.ng

1 Department of Biochemistry, Federal University of Technology, P.M.B. 65, Minna, Niger State, Nigeria

2 Nutrition and Toxicology Division, Federal Institute of Industrial Research, Oshodi, P.M.B. 21023, Lagos, Ikeja, Nigeria and their complications (Brownlee 2001). In addition, antioxidant mechanisms which may alleviate oxidative stress are diminished in diabetic patients. Antioxidants are known to be significant in the treatment and control of DM and its complications. A diversity of local herbs and vegetables consumed by man is known to contribute significantly to the enhancement of human health either in prevention and/or cure of diseases because plants have for a long time served as a useful and natural source of therapeutic agents (Roberts and Tyler 1999). This has been attributed to their phytochemical and nutritional constituents. Among such plants is Celosia argentea var. Cristata L. (CAVCL).

C. argentea (family: Amaranthaceae) is a broad leafy vegetable commonly known as quail grass, feather cockscomb, and Lagos spinach. It is known locally as Soko Yokoto by the Yoruba-speaking ethnic group of Nigeria. It is known to grow very well in temperate and tropical regions (Yarger 2007). It is widespread through northern South America, the West Indies, tropical Africa, and tropical Asia where it matures as a wild flower. In the traditional medical practice, the decoctions of $C$. argentea seeds have been shown to be useful in the treatment 
of many diseases including jaundice, inflammation, healing of wounds, injuries, and diabetes mellitus Shah et al. 1993). Alcoholic extracts of the roots and seeds have been reported to possess antipyretic, anticancer, antidiabetic, antibacterial, diuretic, and antispasmodic properties (Vetrichelvan et al. 2002).

Although $C$. argentea decoction is demonstrated in folkloric medicine in the treatment of diabetes, there are, however, few scientific studies to evaluate its antidiabetic property. This study, therefore, is designed to further validate the hypoglycemic and antioxidant properties of this plant.

\section{Materials and method}

\section{Reagent and chemicals}

Trichloroacetic acetic acid (Sigma, London), thiobarbituric acid (Sigma, London), potassium chloride, (BDH Chemical ltd. England), Alloxan monohydrate (Sigma Chemical Co. St. Louis, MO, USA), Glibenclamide (Dana Pharmaceutical Company, Lagos), Randox Diagnostic kits for alanine amino transferase (ALT), aspartate aminotransferase (AST), Techo Diagnostic kit for Alkaline phosphatase (ALP).

\section{Plant materials}

The plant was purchased from Ile-Epo market, Lagos, Nigeria, and was authenticated at Department of Botany, University of Lagos, Lagos, Nigeria. A voucher number LUH5435 was assigned and deposited in the herbarium.

The leaves were dried under room temperature and pulverized using an electric blender.

\section{Plant extraction}

A portion of the powder $50 \mathrm{~g}$ was extracted with $300 \mathrm{ml}$ of methanol. The extract was filtered using muslin cloth and Whatman's no. 1 filter paper (Maidstone, UK) and concentrated in vacuo.

\section{Experimental animals}

Male and female albino rats weighing 130-180 g were used for this study. The rats were obtained from Zoology Department, University of Ilorin, Ilorin, Nigeria. They were nourished ad libitum on feed manufactured by top feeds, Minna, and were acclimatized for 2 weeks in the Biochemistry Department Laboratory of Federal University of Technology, Minna, Nigeria. All animals were fasted overnight before commencement of the experiment.
These studies were carried out under the approval and guidelines of the ethical committee of the Federal University of Technology, Minna, Nigeria, in agreement to the Declaration of Helsinki.

\section{Acute toxicity and behavioral pattern studies}

Acute toxicity study was carried out according to Organization for Economic Co-operation and Development (OECD 2009) guideline (OECD, 423). Thirty albino rats were grouped into six consisting of five animals each. The animals were fasted overnight (i.e., away from food only; water was not withdrawn) prior to dosing. Groups I-III received a single dose of 10,100 , and $1000 \mathrm{mg} / \mathrm{kg}$ b.w of the extract respectively, while groups IV-VI received 1600, 2000, and $5000 \mathrm{mg} / \mathrm{kg}$ respectively.

Animals were observed individually for the first $30 \mathrm{~min}$ with special attention being given in the first $4 \mathrm{~h}$ within $24 \mathrm{~h}$ and daily, thereafter, for the next 14 days for general behavioral, physiological, and pharmacological changes as well as lethality.

\section{Induction of diabetes}

Experimental diabetes was induced in 20 out of 25 male albino rats by intraperitoneal injection of $120 \mathrm{mg} / \mathrm{kg}$ b.w alloxan monohydrate (Sigma Chemical Co. St. Louis, MO, USA) dissolved in normal saline. Diabetes was established by glucose oxidase method using the glucometer (Accu-check®) $72 \mathrm{~h}$ after alloxan injection. Rats with blood glucose level $\geq$ $200 \mathrm{mg} / \mathrm{dl}$ were isolated and used for this study.

\section{Experimental design}

The rats were randomly allocated into five groups consisting of five rats each:

Group A: were given distilled water and served as the control

Group B: were diabetic and treated with $250 \mathrm{mg} / \mathrm{kg}$ b.w methanolic extract of $C$. argentea

Group C: diabetic and treated with $750 \mathrm{mg} / \mathrm{kg}$ b.w methanolic extract of $C$. argentea

Group D: diabetic and treated with $5 \mathrm{mg} / \mathrm{kg}$ b.w. Glibenclamide (standard drug)

Group E: diabetic and received distilled water (Diabetic control)

Blood glucose was estimated once every week using a glucometer (ACCU-CHECK®). Administration of treatment was for a period of 3 weeks. At the end of the experimental 
Table 1 Acute toxicity effect of methanolic extract of Celosia argentea var. cristata $L$. leaves

\begin{tabular}{llll}
\hline $\begin{array}{l}\text { Dose level } \\
(\mathrm{mg} / \mathrm{kg})\end{array}$ & $\begin{array}{l}\text { Parameters } \\
\text { monitored }\end{array}$ & $\begin{array}{l}\text { Cage side } \\
\text { observation }\end{array}$ & Mortality \\
\hline 10 & Condition of the fur/skin & Normal & NIL \\
100 & Eye dullness and ptosis & NIL & NIL \\
1000 & Breathing abnormality & NIL & NIL \\
1600 & Color and consistency of feces & Normal & NIL \\
2000 & Gait & Normal & NIL \\
5000 & Abdominal distension & NIL & NIL \\
\hline
\end{tabular}

period, they were fasted for $12 \mathrm{~h}$ and blood was collected by cardiac puncture under light anesthesia.

Serum was collected after centrifugation of blood samples at $2000 \mathrm{rpm}$ for $10 \mathrm{~min}$ using bench centrifuge.

The excised liver of each animal was rinsed in ice cold $1.15 \% \mathrm{KCL}$ solution, blotted and weighed. Homogenization of weighed liver was done with $0.1 \mathrm{M}$ phosphate buffer $(\mathrm{pH} 7.2)$ and the resulting homogenate was centrifuged at $2500 \mathrm{rmp}$ for $15 \mathrm{~min}$ at $4{ }^{\circ} \mathrm{C}$. The supernatants were decanted and stored at $-20^{\circ} \mathrm{C}$ until analysis.

\section{Serum hepatic biomarkers}

Serum ALT and AST levels were determined using enzyme diagnostic kits, colorimetric method obtained from Randox (Reitman and Frankel 1957). Serum ALP activity was assayed using colorimetric endpoint method (1976) using Teco Diagnostic kits.

\section{Antioxidative activity}

The homogenized hepatic tissues were assayed for oxidative stress marker enzymes vis-à-vis superoxide dismutase (SOD) (Misra and Fridovich 1972) and catalase activities (Sinha 1972).
Lipid peroxidation was analyzed by measuring the malondialdehyde (MDA) level of the hepatic tissue as described by Buege and Aust (1978).

\section{Statistical analysis}

All values were expressed as mean $\pm \mathrm{SD}$ of three animals per group. Statistical analysis was performed using one-way analysis of variance (ANOVA) and individual comparisons of the group mean values were done using Duncan's test.

\section{Results and discussion}

The cost of treating DM remains a bane in most developing countries, owing to their low economy status. This has led to increased rate of morbidity and mortality, thus the search for cheap affordable drugs with few or no side effects. In this study, we investigated the anti-hyperglycemic effect of the methanolic extract of $C$. argentea leaves vis-à-vis antioxidative and hepatic protective effects.

The test animals showed no significant signs of toxicity and changes in behavior before and after the administration of an oral dose of the methanolic extract of CAVCL leave as shown in Table 1. No mortality was recorded even at the highest dose, thus signifying that the extract has no toxic effect in rats.

Table 2 Effect of methanolic extract of Celosia argentea var. cristata L. leaves in alloxan induced diabetic rats

\begin{tabular}{lllll}
\hline Treatment groups & Initial blood glucose & Blood glucose at day seven & Blood glucose at day fourteen & Blood glucose at day twenty one \\
\hline A & $83.66 \pm 4.16^{\mathrm{a}}$ & $81.00 \pm 2.64^{\mathrm{a}}$ & $86.66 \pm 5.68^{\mathrm{a}}$ & $85.00 \pm 9.53^{\mathrm{a}}$ \\
B & $457.00 \pm 8.88^{\mathrm{b}}$ & $172.00 \pm 9.84^{\mathrm{c}}$ & $235.67 \pm 7.67^{\mathrm{b}}$ & $103.33 \pm 17.47^{\mathrm{a}}$ \\
C & $487.00 \pm 25.98^{\mathrm{b}}$ & $133.66 \pm 11.15^{\mathrm{b}}$ & $248.33 \pm 9.50^{\mathrm{b}}$ & $85.00 \pm 5.19^{\mathrm{a}}$ \\
D & $555.67 \pm 33.40^{\mathrm{c}}$ & $171.35 \pm 8.62^{\mathrm{c}}$ & $328.00 \pm 23.30^{\mathrm{c}}$ & $104.33 \pm 10.40^{\mathrm{c}}$ \\
E & $468.00 \pm 46.22^{\mathrm{b}}$ & $252.33 \pm 7.76^{\mathrm{b}}$ & $254.00 \pm 7.00^{\mathrm{b}}$ & $250.33 \pm 6.65^{\mathrm{b}}$
\end{tabular}

Values with superscript different from the normal control are significantly different $(p<0.05)$. Values are mean of 3 determinations $\pm \mathrm{SD}$.

Keys: $\mathrm{A}=$ normal control group, $\mathrm{B}=$ diabetic $+250 \mathrm{mg} / \mathrm{kg}$ b.w CAVCL, $\mathrm{C}=$ Diabetic $+750 \mathrm{mg} / \mathrm{kg}$ b.w CAVCL, D $=$ Diabetic + Glibenclamide $5 \mathrm{mg} / \mathrm{kg}$ b.w, $\mathrm{E}=$ Diabetic control 
Fig. 1 a Effect of methanolic extract of CAVCL on serum alanine transaminase concentration in alloxan-induced diabetic rats. b Effect of methanolic extract of CAVCL on serum aspartate transaminase concentration in alloxan-induced diabetic rats. $\mathbf{c}$ Effect of methanolic extract of CAVCL on alkaline phosphatase concentration in alloxan-induced diabetic rats
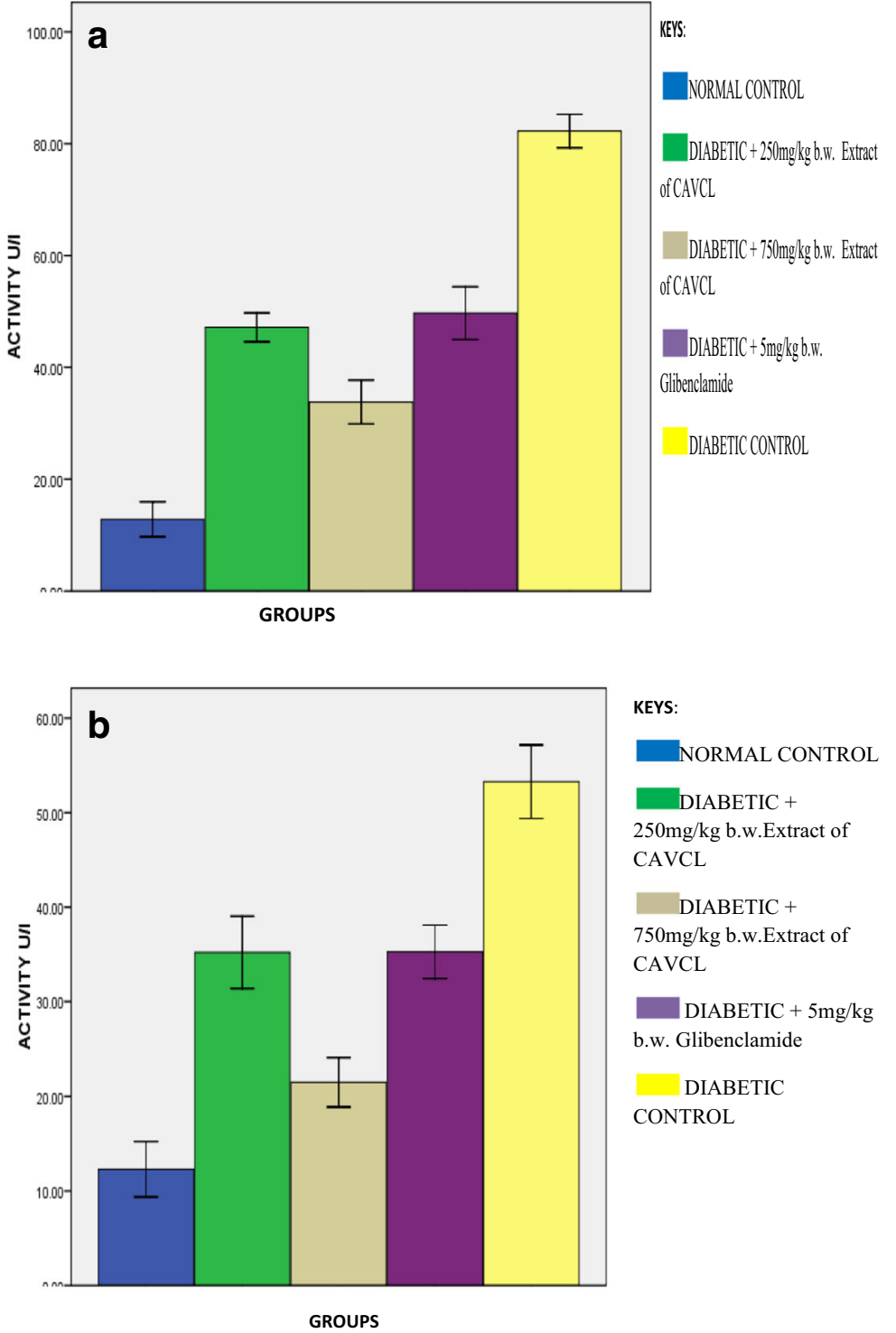

KEYS:

NORMAL CONTROL

DIABETIC +

$250 \mathrm{mg} / \mathrm{kg}$ b.w.Extract of CAVCL

DIABETIC +

$750 \mathrm{mg} / \mathrm{kg}$ b.w.Extract of CAVCL

DIABETIC $+5 \mathrm{mg} / \mathrm{kg}$ b.w. Glibenclamide

DIABETIC CONTROL

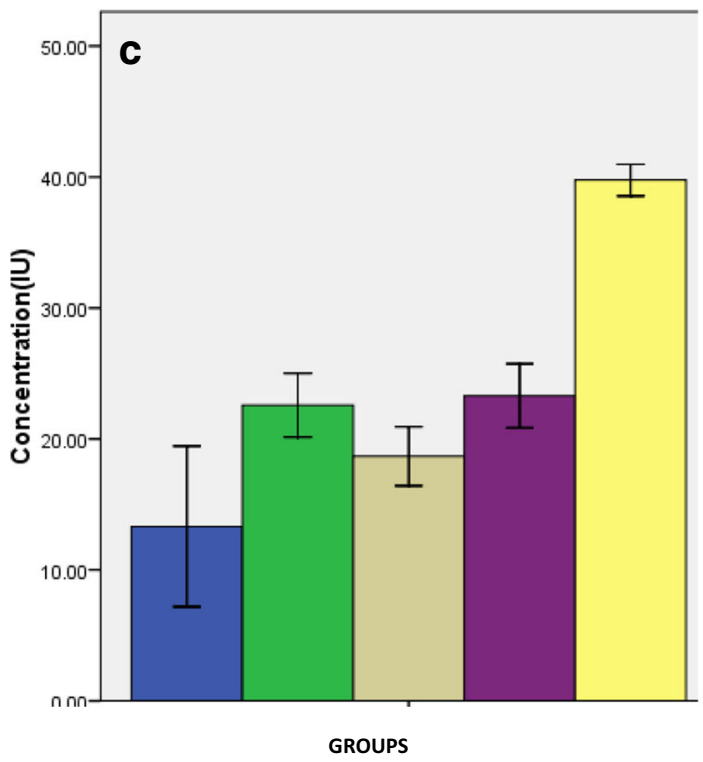

KEYS

NORMAL CONTROL

DIABETIC + $250 \mathrm{mg} / \mathrm{kg}$ b.w.Extract of CAVCL

DIABETIC + $750 \mathrm{mg} / \mathrm{kg}$ b.w.Extract of CAVCL

DIABETIC + $5 \mathrm{mg} / \mathrm{kg}$ b.w. Glibenclamide DIABETIC CONTROL 
Induction of diabetes led to significant increase $(p<0.05)$ in blood glucose level of $250.33 \pm 6.65 \mathrm{mg} / \mathrm{dL}$ compared to the normal control group as depicted in Table 2. Treatment with glibenclamide, C. argentea extracts at 250 and $750 \mathrm{mg} /$ $\mathrm{kg}$ b.w. resulted to a significant reduction to $104.33 \pm 10.40$, $103.33 \pm 17.47$, and $85.00 \pm 5.19 \mathrm{mg} / \mathrm{dL}$ respectively (Table 2). This result compares favorably with the work of Edoga et al. (2013), which reported that the aqueous extract of Moringa oleifera leaves do possess a significant hypoglycemic activity in normo-glycemic and alloxan-induced diabetic rats in a dose-dependent manner and was almost comparable to the standard drug. Although no mechanism of action of C. argentea extract on blood glucose has been proposed, its mode of action may be due to presence of active compounds which imitate insulin action in the same manners as sulphonylureas that stimulate insulin secretion via closure of $\mathrm{K}^{+}$-ATP channels and stimulation of $\mathrm{Ca}^{2+}$ influx (Latha and Pari 2003).

Serum levels of ALT, AST, and ALP were significantly $(p<0.05)$ high in diabetic control group compared with the normal group. The increased serum levels of these enzymes indicate an occurrence of hepatic injury (Erukainure et al. 2015). They are released into the blood stream due to inflammation of the liver. Administration of $C$. argentea extract at both doses and glibenclamide was able to reduce appreciably the elevated level of ALT (Fig. 1a). Significant reduction in aspartate transaminase level was observed for the groups administered with $250 \mathrm{mg} / \mathrm{kg}$ b.w $C$. argentea extract and glibenclamide. While serum ALP levels were reduced to near normal as shown in Fig. 1c, these reduced levels correspond to previous reports of Suneetha and Susatha (2010) who reported that the stem juice of Musa paradisiaca was able to significantly reduce the elevated levels of serum hepatic biomarkers in alloxan-induced diabetic rats after 21day treatment in a dose-dependent manner. These results thus suggest a protective effect of the extract against hepatic injury.

Induction of diabetes led to significant $(p<0.05)$ decrease in catalase and SOD activities as depicted in Figs. 2 and 3 respectively. These were significantly $(p<0.05)$ reversed on treatment with the extract and glibenclamide. Both SOD and catalase are major free radical-scavenging enzymes (Manonmani 2004). Their activities are usually little in diabetes mellitus (Vucic et al. 1997). The increased activities correspond to previous reports by Hamzah et al. (2012) on increased serum hepatic biomarkers in Peperomia pellucidatreated diabetic rats. The reduced SOD activity on induction of diabetes can be attributed to the unswerving harmful effect of free radicals on the enzyme or the diabetogenic agent alloxan. Previous studies have revealed the presence of an appreciable amount of iron, copper, and zinc in $C$. argentea plant (Chionyedua et al. 2009). Therefore, ability of this plant to increase catalase and superoxide dismutase activities can be attributed to the induction of the enzyme by these micronutrients as iron and $\mathrm{Cu} / \mathrm{Zn}$ are metal cofactors for CAT and SOD respectively.

There was significant $(p<0.05)$ increase in MDA level on induction of diabetes, indicating an occurrence of lipid peroxidation as shown in Fig. 4. The increased MDA level can be attributed to the reduced SOD and catalase activities (Figs. 2 and 3) and may be responsible for the increased
Fig. 2 Effect of methanolic extract of CAVCL on catalase activities in alloxan-induced diabetic rats

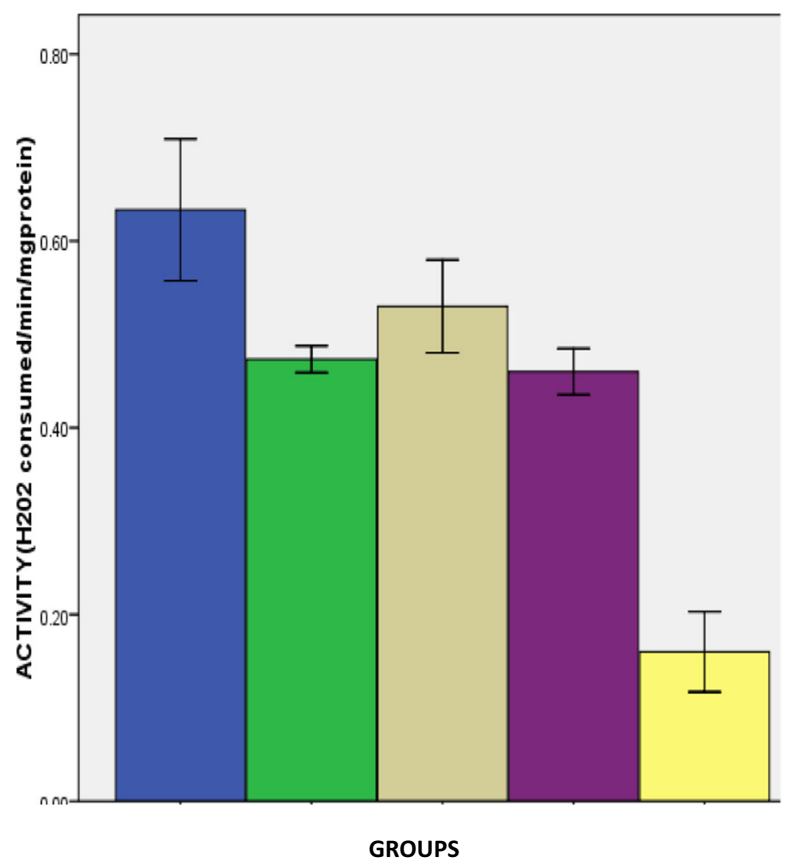

KEYS:

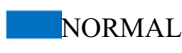
CONTROL

DIABETIC + $250 \mathrm{mg} / \mathrm{kg}$ b.w.Extract of CAVCL

DIABETIC + $750 \mathrm{mg} / \mathrm{kg}$ b.w.Extract of CAVCL

DIABETIC + $5 \mathrm{mg} / \mathrm{kg}$ b.w. Glibenclamide

DIABETIC CONTROL 
Fig. 3 Effect of methanolic extract of CAVCL on superoxide dismutase activities in alloxaninduced diabetic rats

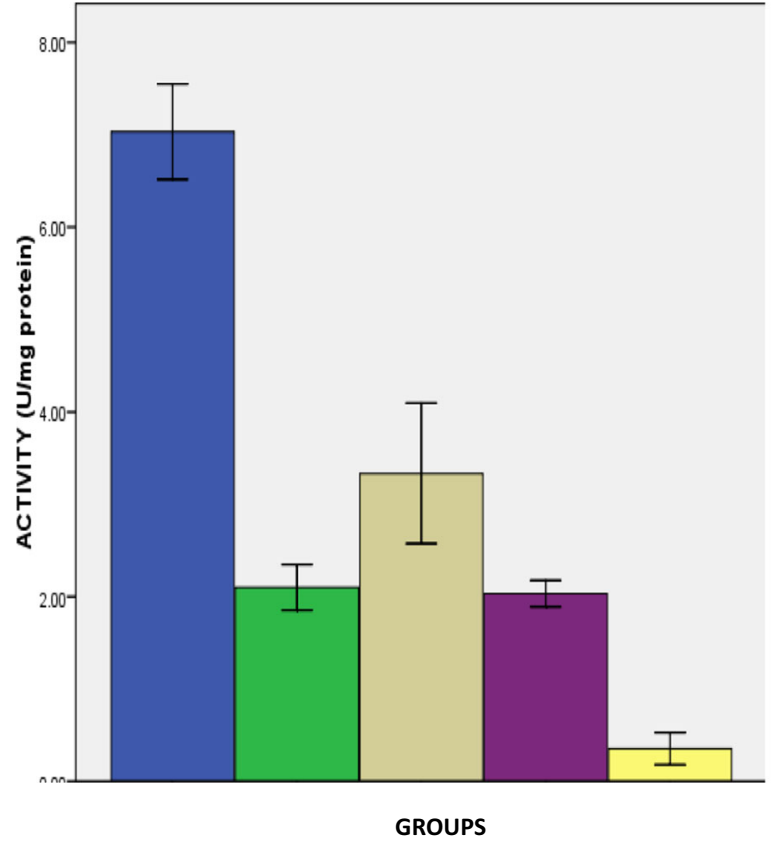

KEYS:

NORMAL CONTROL

DIABETIC + $250 \mathrm{mg} / \mathrm{kg}$ b.w.Extract of CAVCL

DIABETIC + $750 \mathrm{mg} / \mathrm{kg}$ b.w.Extract of CAVCL

DIABETIC +

$5 \mathrm{mg} / \mathrm{kg}$ b.w.

Glibenclamide

DIABETIC

CONTROL serum levels of hepatic biomarkers (Fig. 1a-c) due to leakage owing to peroxidation of hepatic membrane lipid. $C$. argentea extract at $750 \mathrm{mg} / \mathrm{kg}$ b.w. was effective in reducing the level of MDA significantly $(p<0.05)$ compared with the other treated groups. This corroborates the reduced serum hepatic biomarkers (Fig. 1a-c) and increased antioxidant activities (Figs. 2 and 3 ) after treatment with C. argentea.

\section{Conclusion}

These results indicate an anti-hyperglycemia and antioxidative protective effect of $C$. argentea leaves, thus giving credence to its folkloric use in the treatment and management of diabetes. However, further studies are required to elucidate the molecular mechanism of action as well as secondary metabolites that may be responsible for these activities.
Fig. 4 Effect of methanolic extract of CAVCL on lipid peroxidation in alloxan-induced diabetic rats

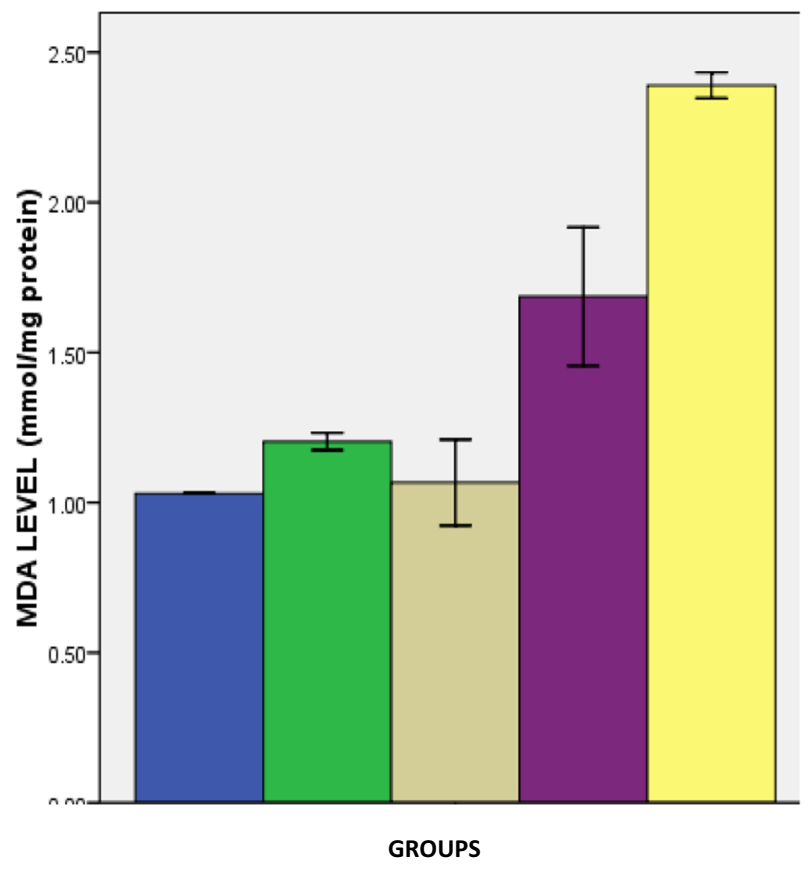

KEYS:

NORMAL CONTROL

DIABETIC + $250 \mathrm{mg} / \mathrm{kg}$ b.w.Extract of CAVCL

DIABETIC + $750 \mathrm{mg} / \mathrm{kg}$ b.w.Extract of CAVCL

DIABETIC + $5 \mathrm{mg} / \mathrm{kg}$ b.w. Glibenclamide

DIABETIC CONTROL 


\section{Compliance with ethical standards}

Ethical approval All procedures performed in this study involving experimental animals were in accordance with the ethical standards of the institutional and/or national research committee and with the 1964 Helsinki declaration and its later amendments or comparable ethical standards.

Conflict of interest The authors declare that they have no conflict of interest.

Open Access This article is distributed under the terms of the Creative Commons Attribution 4.0 International License (http:// creativecommons.org/licenses/by/4.0/), which permits unrestricted use, distribution, and reproduction in any medium, provided you give appropriate credit to the original author(s) and the source, provide a link to the Creative Commons license, and indicate if changes were made.

\section{References}

Brownlee M (2001) Biochemistry and molecular cell biology of diabetic complications. Nature 414:813-820

Buege JA, Aust SD (1978) Microsomal lipid peroxidation. Methods Enzymol 52:302-310

Chionyedua TO, Anuoluwa MO, Adedoja DW (2009) The proximate and mineral composition of three leafy vegetables commonly consumed in Lagos, Nigeria. Afr J Pure Appl Chem 3(6):102-107

Edoga CO, Njoku OO, Amadi EN, Okeke JJ (2013) Blood sugar lowering effect of Moringa Oleifera Lam in albino rats. Int J Sci Technol 3(1):88-90

Erukainure OL, Ebuehi OA, Adeboyejo FO et al (2013) Fiber-enriched biscuit enhances insulin secretion, modulates $\beta$-cell function, improves insulin sensitivity, and attenuates hyperlipidemia in diabetic rats. PharmaNutrition 1(2):58-64
Erukainure OL, Ebuehi OA, Adeboyejo FO et al (2015) Short-term feeding of fibre enriched biscuits: protective effect against hepatotoxicity in diabetic rats. Biochem Res Int. https://doi.org/10.1155/2015/86893

Hamzah RU, Odetola AA, Ochuko LE (2012) Peperomia pellucida in diets modulates hyperglyceamia, oxidative stress and dyslipidemia in diabetic rats. J Acute Dis 1(2):135-140

Latha M, Pari L (2003) Anti-hyperglycemic effect of Cassia auriculata in experimental diabetes and its effect on key metabolic enzymes involved in carbohydrate metabolism. Clin Exp Pharmacol Physiol 30:38-43

Manonmani M (2004) Ph.D Thesis. Tamil Nadu Agricultural University. Coimbatore, India

Misra HP, Fridovich I (1972) The role of superoxide anion in the autoxidation of epinephrine and a simple assay for superoxide dismutase. J Biochem 25(247(10)):22-3175

Organisation for Economic Co-operation and Development (OECD) (2009) Test No. 423: Acute oral toxicity — acute toxic class method, OECD Guidelines for the Testing of Chemicals. OECD Publishing, Paris, pp 1-10

Reitman S, Frankel S (1957) A colorimetric method for the determination of serum glutamic oxalacetic and glutamic pyruvic transaminases. Am J Clin Pathol 28(1):56-63

Roberts JE, Tyler VE (1999) Tyler's herbs of choice. The therapeutic use of phytonedicinals, vol 11. The Haworth Herbal Press, New York

Shah MB, Patel KN, Chauhan MG (1993) Contribution to indigenous drugs. I: Celosia argentea. Int J Pharmocog 31:223-234

Sinha AK (1972) Colorimetric assay of catalase. Anal Biochem 47:389394

Suneetha B, Susatha D (2010) Antidiabetic and antioxidant activities of stem juice of Musa Paradisiaca on alloxan induced diabetic rats. Int $\mathbf{J}$ Adv Pharm Sci 5(2):1-3

Vetrichelvan T, Jegadeesan M, Devi B (2002) Anti-diabetic activity of alcoholic extract of Celosia argentea L. seeds in rats. Asian J Biomed 25:526-528

Vucic M, Gavella M, Bozikov V, Ashcroft SJ, Rocic B (1997) Superoxide dismutase activity in lymphocytes and polymorphonuclear cells of diabetic patients. Eur. J. Clin. Chem Clin. Biochem 35:517-521

World Health Organization (1999) Diagnosis and classification of diabetes (part 1): a report on WHO consultation, Geneva 1-49

Yarger L (2007) Lagos spinach. Echo Tech Note:1-8 